\title{
Focus on Food Safety: Human Pathogens on Plants
}

\author{
Maria T. Brandl (Senior Editor) and George W. Sundin (Editor-in-Chief)
}

First author: Produce Safety and Microbiology Research Unit, United States Department of Agriculture-Agriculture Research Service, Albany, CA; and second author: Department of Plant, Soil, and Microbial Sciences, Michigan State University, East Lansing, MI.

We are pleased to introduce the first Focus Issue of Phytopathology, a dedicated issue of the journal that highlights a topic of significant interest to our readership. Focus Issues will contain invited review and invited perspective articles as well as original research articles, and will appear with a frequency of once every 18 to 24 months. All published manuscripts are subject to the normal peer review process for publication in Phytopathology. This first Focus Issue addresses the topic of food safety and the biology of human pathogens on plants, a relatively new problem with a direct impact on public health. In addition, the interest of the Editorial Board of Phytopathology in publishing manuscripts on this topic led to the inclusion of Human Pathogens on Plants as a new section of the journal. As is evidenced below and discussed in the perspective article by Fletcher et al. (3, pages 306-315), this critical aspect of produce safety is relevant to research in plant microbial ecology and intersects with numerous concepts that are explored in plant pathology.

The emergence of outbreaks of human illness linked to the contamination of produce is likely one of the most important problems to face horticultural production at the beginning of this century. Epidemics of foodborne disease are not only a threat to public health but also erode consumer confidence in the causal food product and thus, impact the economic viability of the industry. While at first considered as anomalous, a recent report by the Centers for Disease Control and Prevention, which revealed that contaminated produce caused $46 \%$ of the individual cases of foodborne illness in the United States between 1998 and 2008 (7), confirmed that the risk of acquiring infections from produce is high and persisting despite increased awareness and prevention measures taken by producers and processors. Although researched extensively for nearly two decades, produce contamination with human pathogens continues to bring many important questions about the behavior of these pathogens on plants and the biotic and abiotic factors that contribute to their persistence in this habitat, thereby causing human illness.

The identification of routes of plant contamination by enteric pathogens is crucial to the design of intervention strategies to prevent contamination from taking place. In this issue, research by Wasala et al. (10, pages 373-380) demonstrates that filth (house) flies, which consume bacteria at the larval state, can acquire Escherichia coli serovar 0157:H7 from inoculated manure and vector the pathogen not only by carrying it on their surface but can also contaminate the spinach phyllosphere through their regurgitated material. Upon landing on the plant surface, enteric pathogens may reside as single solitary cells or in a community of established epiphytic microbes. The elegant study by Poza-Carrion et al. (8, pages 341-351) reveals by quantitative analysis of epifluorescence micrographs that established epiphytic bacteria such as Pseudomonas fluorescens and Erwinia herbicola (Pantoea agglomerans) influence the ability of Salmonella enterica to persist on plants. These bacterial species promoted the survival to desiccation conditions of $S$. enterica cells immigrating in their close vicinity on lettuce and cilantro leaves, potentially by modulat-

http://dx.doi.org/10.1094/PHYTO-103-4-0304 ing the immediate physicochemical environment at microsites where the pathogen arrived in the phyllosphere. Hence, interactions between human pathogens and indigenous plant microbes, whether directly or indirectly, may affect the outcome of a contamination event. Cox et al. (2, pages 352-361) hypothesized that such an interaction between $S$. enterica and Pectobacterium carotovorum, which causes lesions that increase multiplication of the human pathogen in tomato fruit, involves cell-cell signaling via autoinducer-2 (AI-2). Using signal-defective mutants of both organisms and a sophisticated signal perception-reporter system, they report that AI- 2 does not appear to be exchanged between the two bacterial species, nor enhance the competitive fitness of the human pathogen, during colonization of tomato soft rotted tissue. However, other molecular factors in S. enterica are known to participate in its colonization of plants, including a new bacterial attachment factor uncovered by Kroupitski et al. (6, pages 362372). The misL gene was one of several $S$. enterica genes identified by recombinase-based in vivo expression technology (RIVET) as induced during cold storage of lettuce and played a role in attachment to lettuce leaf tissue. Because MisL is involved also in binding to fibronectin in animal hosts, their observation supports the conclusion in the review by Brandl et al. (1, pages 316-325) that this highly adaptable enteric pathogen employs overlapping strategies to colonize both its primary and secondary habitats.

The ingress of enteric pathogens into plant tissue has been a topic of considerable interest in produce safety. In this Focus Issue, Roy et al. (9, pages 326-332) demonstrate that access to the leaf interior via stomata differs between $S$. enterica and $E$. coli O157:H7, likely because of differences in stomatal immunity to the two pathogens. Their findings provide further mechanistic evidence that plant basal defense responses can shape early interactions between human pathogens and plants, a field of research in produce safety that is receiving increasing attention. In this respect, the observation by Wright et al. (11, pages 333-340) that E. coli $\mathrm{O} 157: \mathrm{H} 7$ forms colonies in the apoplastic space of root tissue and occasionally inside root cells will undoubtedly trigger many new scientific questions about the ability of enteric pathogens to invade plant cells. It will be tempting to surmise, based on data presented by Gu et al. (4, pages 381-388), that highly diverse endophytic bacterial communities promoted by healthy soil management practices may contribute to minimize the probability of such internalization events by foodborne pathogens. Finally, the article by Hirneisen and Kniel (5, pages 389-394) reminds us that while much of the focus in produce safety research has been on plant contamination with bacterial enteric pathogens, noroviruses, which cause a large percentage of the produce-linked outbreaks in the United States (7), have the potential to persist in the phyllosphere. Their observations should provide fascinating new territories to explore the biology of human enteric viruses on plants.

We would like to thank all of the authors for contributing excellent articles to this first Focus Issue of Phytopathology and hope that, as readers who are vested in research in plant pathology, microbial ecology, food microbiology, or medical microbiology, you will find this collection of articles a valuable source of information and inspiration to formulate new hypotheses in plant microbiology. 


\section{LITERATURE CITED}

1. Brandl, M. T., Cox, C. E., and Teplitski, M. 2013. Salmonella interactions with plants and their associated microbiota. Phytopathology 103:316-325.

2. Cox, C. E., McLelland, M., and Teplitski, M. 2013. Consequences of disrupting Salmonella AI-2 signaling on interactions within soft rots. Phytopathology 103:352-361.

3. Fletcher, J., Leach, J. E., Eversole, K., and Tauxe, R. 2013. Human pathogens on plants: Designing a multidisciplinary strategy for research. Phytopathology 103:306-315.

4. Gu, G., Cevallos-Cevallos, J. M., Vallad, G. E., and van Bruggen, A. H. C. 2013. Organically managed soils reduce internal colonization of tomato plants by Salmonella enterica serovar Typhimurium. Phytopathology 103:381-388.

5. Hirneisen, K. A., and Kniel, K. E. 2013. Norovirus surrogate survival on spinach during preharvest growth. Phytopathology 103:389-394.

6. Kroupitski, Y., Brandl, M. T., Pinto, R., Belausov, E., Tamir-Ariel, D., Burdman, S., and Sela (Saldinger), S. 2013. Identification of Salmonella enterica genes with a role in persistence on lettuce leaves during cold storage by recombinase-based in vivo expression technology. Phytopathology 103:362-372.

7. Painter, J. A., Hoekstra, R. M., Ayers, T., Tauxe, R. V., Braden, C. R., Angulo, F. J., and Griffin, P. M. 2013. Attribution of foodborne illnesses, hospitalizations, and deaths to food commodities by using outbreak data, United States, 1998-2008. Emerging Infect. Dis. 19(3):407-415. DOI: 10.3201/eid1903.111866

8. Poza-Carrion, C., Suslow, T., and Lindow, S. 2013. Resident bacteria on leaves enhance survival of immigrant cells of Salmonella enterica. Phytopathology 103:341-351.

9. Roy, D., Panchal, S., Rosa, B. A., and Melotto, M. 2013. Escherichia coli O157:H7 induces stronger plant immunity than Salmonella enterica Typhimurium SL1344. Phytopathology 103:326-332.

10. Wasala, L., Talley, J. L., DeSilva, U., Fletcher, J., and Wayadande, A. 2013. Transfer of Escherichia coli O157:H7 to spinach by house flies, Musca domestica (Diptera: Muscidae). Phytopathology 103:373-380.

11. Wright, K. M., Chapman, S., McGeachy, K., Humphris, S., Campbell, E., Toth, I. K., and Holden, N. J. 2013. The endophytic lifestyle of Escherichia coli O157:H7: Quantification and internal localization in roots. Phytopathology 103:333-340. 